\title{
La llum, vista a través de l'electrodinàmica quàntica
}

\author{
Ramón Corbalán \\ Departament de Física. Grup d'Òptica (Universitat Autònoma de Barcelona)
}

El premi Nobel de física del 2005 es va concedir a tres investigadors en el camp de l'òptica quàntica. És sorprenent el que actualment s'arriba a fer amb la llum, treballant en l'àmbit de l'electrodinàmica quàntica.

Per als que no coneixen l'òptica com a disciplina científica pot semblar que d'ella no se'n pugui esperar gran cosa més, a part de la construcció d'aparells òptics (microscopis, telescopis...). El camp de l'òptica pot semblar una parcel-la de coneixement molt estabilitzada i que ofereix poques sorpreses interessants. I en realitat no és així.

Precisament alguns avenços en aquest terreny han estat premiats amb el darrer premi Nobel de física.

Quan el concepte de fotó complia cent anys, els nord-americans Roy J. Glauber, John L. Hall i l'alemany Theodor W. Hänsch (fig. 1) van rebre el premi Nobel de Física del 2005 pels seus treballs sobre òptica, de caire teòric en el primer, i experimental en els altres dos.

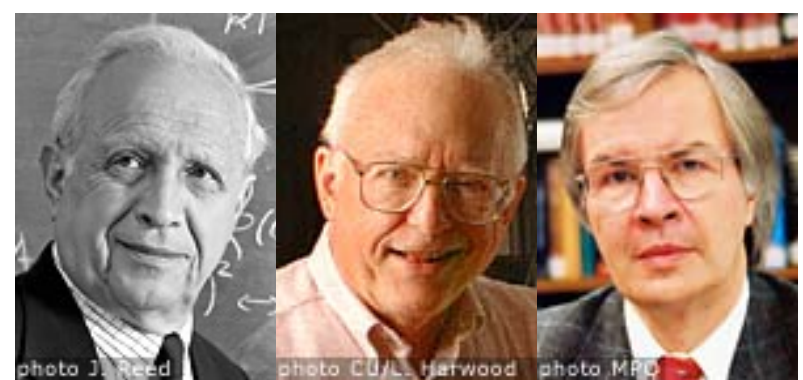

Figura 1. D'esquerra a dreta: Glauber, Hall i Hänsch (http://nobelprize.org/)

Aprofitarem l'ocasió per repassar breument com ha anat canviant la nostra concepció del que és la llum.

Els fenòmens òptics ens han fascinat des de l'antiguitat més remota. La curiositat per estudiar la naturalesa de la llum ha estat un dels grans motors del progrés de la física. Avui dia, aquesta curiositat continua, i el progrés de la física també.

\section{Del segle XVII al naixement de l'Òptica Quàntica}

El segle XVII va viure la controvèrsia entre ona $i$ partícula com a model per a la llum. Per una banda hi havia els que, com Descartes i Huygens, pensaven en un moviment ondulatori semblant al so, i per l'altra els que es decantaven per imaginar la llum constituïda per un flux de partícules.

Tot i la influent autoritat de Newton, partidari d'aquesta darrera opció, de mica en mica el treball experimental va anar decantant la balança a favor de la teoria ondulatòria.

A finals del segle XIX, quan Maxwell establia la teoria electromagnètica, la llum es va considerar unànimement una ona electromagnètica. La resposta semblava clara i definitiva. Però al cap de poc ja no ho va ser.

\section{La llum i la física quàntica}

Efectivament, l'any 1900 Planck, per poder explicar l'espectre d'emissió dels cossos calents, va introduir la idea que la llum o radiació tèrmica s'emetia i absorbia de manera discreta, en forma de quanta de llum.

El 1905, Einstein generalitza la idea de Planck: la llum no només és discreta quan s'emet i s'absorbeix, sinó que també es propaga en forma de quàntums de llum: els fotons. Això li va permetre explicar les propietats de l'efecte fotoelèctric, que és l'emissió d'electrons des de la superfície d'un metall quan és il-luminada amb una radiació de longitud d'ona prou curta. Actualment la majoria dels detectors de llum es basen en l'efecte fotoelèctric.

D'aquesta manera apareixia, per a la llum, l'anomenada dualitat ona-corpuscle. La llum, tot i que en 
molts experiments es comporta com a ona, en d'altres ho fa com si fos un flux de partícules.

No cal dir que aquestes dues formes de concebre la llum són incompatibles en el marc de la física clàssica. Això va fer buscar noves concepcions: la revolució quàntica portaria al desenvolupament d'una nova física, capaç d'integrar en un sol objecte físic tant el comportament corpuscular com l'ondulatori.

És prou sabut que a la dècada de 1920 De Broglie va generalitzar la idea de dualitat estenent-la també al comportament de les partícules materials. Posteriorment Heisenberg, Schrödinger i Dirac, entre altres, van posar els fonaments de la Mecànica Quàntica.

\section{L'electrodinàmica quàntica, QED}

Pel que fa a la llum, el pas següent va ser posar les bases de l'anomenada Electrodinàmica Quàntica (QED, Quantum Electrodynamics) no relativista. Es tracta de la teoria que estudia la interacció entre la llum quantitzada i els electrons, ja siguin lliures o formant part dels àtoms.

Utilitzant-la, Wigner i Weisskopf, a la dècada de 1930, van estudiar l'emissió espontània de llum des dels àtoms, però van topar per primera vegada amb dificultats matemàtiques que tant havien de dificultar el desenvolupament d'aquesta teoria. Així, quan tractaven de calcular el valor de certs canvis en l'energia d'un electró atòmic deguts a la seva interacció o acoblament amb el buit, apareixien valors infinits que no es corresponien amb la realitat. (Aquests canvis en l'energia electrònica s'anomenen desplaçaments radiatius o Lamb shifts).

És important assenyalar que en el model quàntic l'energia del buit no és zero, com intuïtivament es podria creure. Es tracta d'una conseqüència del principi d'indeterminació, que impedeix conèixer simultàniament amb tota precisió la posició i el moment lineal, o altres parelles de magnituds que compleixen el principi d'incertesa, com el camp elèctric i el magnètic. Un i altre camps no poden ser zero alhora. Fins i tot sense cap mena de llum, sempre hi ha un cert camp elèctric i magnètic. Així, un electró lliure en realitat no ho és, de lliure, ja que està interaccionant amb el buit.

(Diguem de passada que si no fos per aquesta energia no nul.la del buit no seria possible l'emissió espontània de llum: un electró excitat estaria en un estat tan estable com en l'estat fonamental i no es produiria la transició. Per això, no es produiria cap de les emissions lluminoses conegudes, excepte les dels làsers, que és estimulada).

Però als anys 40 Tomonaga, Schwinger i Feynman van aconseguir de resoldre el problema dels infinits que apareixien a la teoria, utilitzant una tècnica anomenada renormalització. La idea bàsica de la renormalització és que els Lamb shifts són deguts només a la diferent forma com interacciona l'electró amb el buit quan està "lliure" i quan està Iligat a un nucli atòmic.

La QED es convertí en la teoria física més precisa que mai s'hagi arribat a desenvolupar.

\section{Aplicació de la QED a l'òptica}

El 1960 es produí la invenció del làser, generalment considerada com una de les més importants consecucions de la física en el segle XX. Per això Townes, Basov i Prokhorov reberen el premi Nobel el 1964.

El 1963 Glauber, motivat pel desenvolupament del làser i convençut que l'òptica havia aportat a la quàntica molt més del que n'havia rebut, va iniciar l'aplicació sistemàtica de la QED als problemes òptics. Contribuí així, juntament amb altres investigaors, al gran desenvolupament que havia de tenir posteriorment l'Òptica Quàntica com a disciplina.

Avui dia la QED és la teoria que millor s'ajusta a les dades experimentals. Precisament en el context d'aquesta teoria els recents premis Nobel Hall i Hänsch han fet importants contribucions al desenvolupament de nous mètodes per produir i mesurar freqüències òptiques amb una precisió que actualment és de 15 xifres significatives i podria arribar a les 18, quan ja quedi limitada pel soroll quàntic associat a l'emissió espontània en els làsers.

Per adonar-se de la precisió espectacular d'aquestes mesures només cal pensar que mesurar amb 15 xifres significatives és equivalent a mesurar una distància d'un milió de quilòmetres $\left(10^{9} \mathrm{~m}\right)$ amb un error menor d'un micròmetre $\left(10^{-6} \mathrm{~m}\right)$.

Sorprenentment, la precisió no només augmenta amb el temps, sinó que ho fa cada vegada més ràpidament (fig. 2).

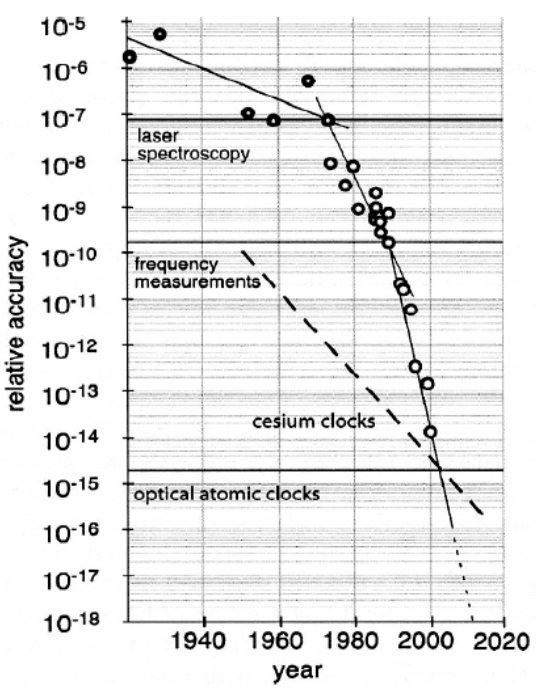

Figura 2. Evolució de la precisió relativa en espectroscopia de precisió al llarg dels anys. 


\section{Algunes línies de recerca}

L'augment de la precisió en les mesures no es persegueix per frivolitat, sinó perquè de vegades posa en evidència nous fenòmens. La història de l'espectroscopia atòmica en proporciona bons exemples.

Així, de l'hidrogen es va descobrir inicialment un espectre de línies discret (fig. 3). Quan el poder de resolució $(v / \Delta v)$ va arribar a $10^{5}$ es va posar de manifest l'anomenada estructura fina de l'espectre, associada a l'espín de l'electró. I amb un poder resolutiu de $10^{7}$ encara s'hi observarien tant els desplaçaments de Lamb o Lamb shifts (fenòmens de QED relacionats amb fluctuacions quàntiques del buit de radiació) com l'estructura hiperfina (HFS), associada a l'espín nuclear.

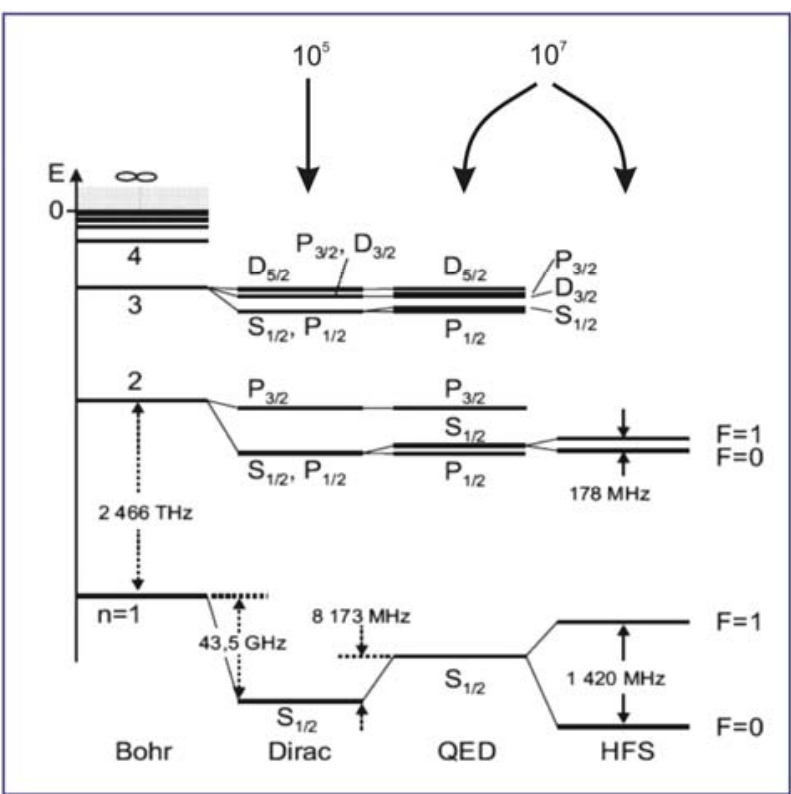

Figura 3. Una part de l'espectre de l'hidrogen. Amb els successius augments del poder de resolució, s'han anat trobant noves característiques en l'espectre de l'hidrogen. A la part superior s'hi indiquen els poders de resolució necessaris $\left(10^{5}\right.$ i $\left.10^{7}\right)$ per observar les diverses estructures de nivells d'energia. La darrera línia mostra els noms de les teories que expliquen cadascun d'aquests avenços experimentals. A la tercera columna, el desdoblament entre els subnivells $\mathrm{S}_{1 / 2}$ i $\mathrm{P}_{1 / 2}$ mostra el desplaçament de Lamb o Lamb shift.

Per això, basant-nos en aquestes experiències prèvies, esperem poder descobrir nous fenòmens no previstos per les teories actuals. Per exemple, s'estan realitzant mesures espectroscòpiques de gran precisió per determinar fins a quin punt les constants físiques són realment estables en el temps. Així, s'ha pogut determinar que una d'elles, la constant d'estructura fina, $\alpha$, en un any no varia més de $10^{-15}$ parts per unitat.

També s'està estudiant si hi ha asimetries entre matèria i antimatèria. Per exemple, analitzant amb gran precisió els espectres de l'hidrogen i de l'antihidrogen (creat en el CERN i format per un antiprotó en el nucli i un positó a l'escorça) es pretén determinar si, tal com prediu la teoria, efectivament els seus espectres són iguals.

I en un aspecte més pràctic, l'augment en la precisió de les mesures de freqüències òptiques s'aplica a millorar la dels rellotges atòmics i, en conseqüència, també dels sistemes GPS, de la navegació espacial o de les xarxes de telescopis astronòmics.

\section{Com es pot refredar un àtom utilitzant Ilum?}

Un àtom a temperatura ambient té una velocitat de l'ordre de $1000 \mathrm{~m} / \mathrm{s}$, però amb llum es pot deixar gairebé aturat. Com és possible, això?

En una primera aproximació, el procediment és semblant a aturar una pilota llançant-hi de cara moltes pilotes de ping-pong molt més lleugeres.

En efecte, es dirigeix un feix de llum làser frontalment contra l'àtom que es vol aturar. Cada fotó té una quantitat de moviment que segons la hipòtesi de De Broglie $(\lambda=h / p)$ val

$$
\mathrm{p}=\frac{h}{\lambda}=\frac{v h}{c},
$$

o sigui que és proporcional a la freqüència.

Es tria la freqüència del raig làser de forma que sigui la justa per produir la transició d'un electró de l'àtom des del seu estat fonamental al següent. Quan l'àtom captura un fotó, aquest li transfereix la seva quantitat de moviment, de signe contrari a la de l'àtom, ja que van en sentits contraris. D'aquesta manera, progressivament anirà perdent velocitat.

Cal dir que una vegada excitat l'electró, aquest torna a l'estat fonamental emetent un altre fotó igual que el que l'havia excitat. Aparentment així tornaria la mateixa quantitat de moviment que havia perdut. És així, però amb la particularitat que si l'absorció es produïa sempre en la mateixa direcció i sentit, ara l'emissió, espontània, es produeix en direccions aleatòries. Això significa que, per probabilitat, la suma de nombrosos d'aquests impulsos és zero.

Com que el temps que triga un electró per fer la transició a l'estat excitat i després tornar de nou al fonamental per emissió espontània és de l'ordre de $10^{-8} \mathrm{~s}$, en un segon un àtom pot arribar a capturar molts milions de fotons. Per això els xocs frontals entre els fotons i l'àtom li produeixen una desacce- 
leració considerable, de l'ordre de $10^{5}$ vegades l'acceleració de la gravetat!

Afinant més, cal tenir en compte l'efecte Doppler. L'efecte combinat de dos làsers que actuen en sentits contraris són forces oposades al moviment, com si l'àtom s'estigués movent dins d'una espècie de melassa viscosa. És per això que aquests dispositius s'anomenen melasses òptiques (optical molasses). La combinació de tres parelles de làsers, en les tres direccions de l'espai, aconsegueix aturar i atrapar els àtoms (fig. 4).

Cal dir que per causa de la naturalesa aleatòria de la emissió espontània, en las melasses òptiques no es pot aconseguir d'aturar del tot els àtoms. Així, la velocitat d'un àtom de sodi no podrà baixar dels $3 \mathrm{~cm} / \mathrm{s}$, que correspon a una temperatura de $240 \mu \mathrm{K}$.

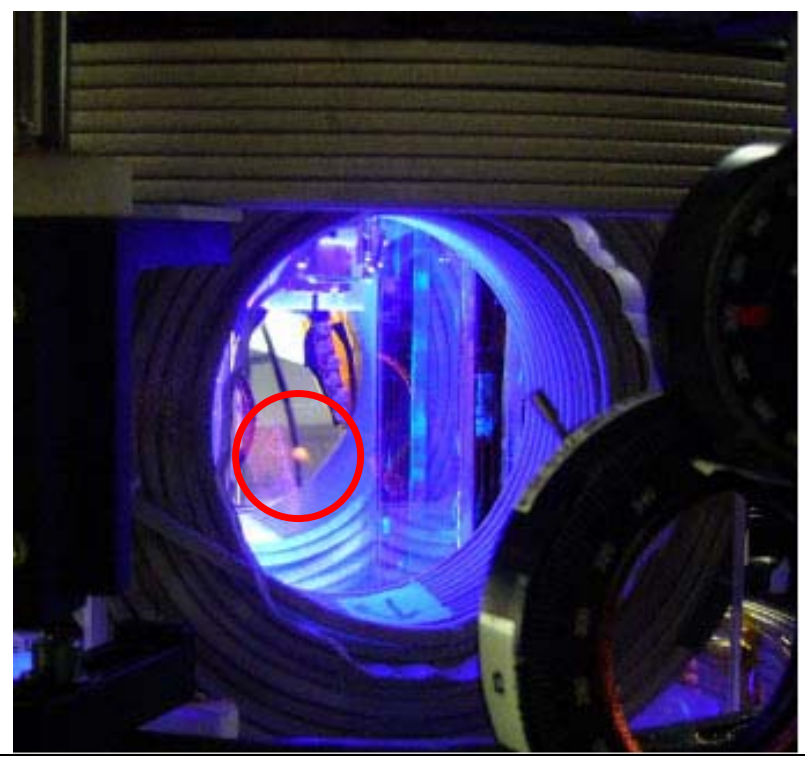

Figura 4. Encerclat amb un cercle vermell es pot veure la massa d'àtoms de rubidi atrapats per tres parells de feixos làser. És visible gràcies a la llum que emeten al ser excitats mitjançant els làsers. (Imatge:

http://www.physics.utoronto.ca/ -jhtgroup/labtour.ht $\underline{\mathrm{ml}})$

\section{Un camp de recerca fructífer}

Com es pot veure, el camp de l'Òptica Quàntica és ben actiu en l'actualitat. N'és una prova que darrerament el premi Nobel de física recaigui cada quatre anys en investigadors d'aquest camp.

Així, el 1997 es concedí a Chu, Cohen-Tannoudji i Phillips pel desenvolupament de mètodes per refredar i confinar àtoms amb llum làser. Aquestes tècniques, suplementades amb un altre mètode de refredament (evaporació forçada), permeteren aconseguir el condensat de Bose-Einstein a temperatures d'uns 500 nK. Per aquest motiu, i pels seus estudis pioners sobre les propietats del condensat, el 2001 foren guardonats Cornell, Ketterle i Wieman.

Els condensats de Bose-Einstein foren predits teòricament el 1924 però no es van obtenir fins al 1995. Mentre que els fermions compleixen el principi d'exclusió de Pauli i no se'n poden superpondre diversos en un sol estat, els bosons sí que ho poden fer. D'aquesta manera, a temperatures prou baixes s'arriba a obtenir un nou estat de la matèria en el qual els àtoms bosònics (aquells que tenen un spin total enter, com és el cas del rubidi-87, l'heli-4 o el sodi-23) perden la seva individualitat i esdevenen indistingibles.

Res de tot això no hauria estat possible sense els avenços que ha proporcionat l'electrodinàmica quàntica, que en la seva versió no relativista és la física bàsica de l'òptica.

\section{Adreces}

Nobel prize:

http://nobelprize.org

Quantum Optics and Spectroscopy. Universität of Innsbruck:

http://www.quantumoptics.at/

Quantum Optics and Atom Optics links: http://www.quantumoptics.net

Physics 2000. University of Colorado at Boulder Website:

http://www.colorado.edu/physics/2000/index.pl

Wikipedia: Laser

http://en.wikipedia.org/wiki/Laser

Lasers. John Watson

http://vcs.abdn.ac.uk/ENGINEERING/lasers/lasers. $\underline{\text { html }}$

National Physical Laboratory. Optical frequency standards and metrology:

http://www.npl.co.uk/optical frequency standards/i ndex.html

National Research Council Canada. Institute for National Measurements Standards. Optical Frequency. Research Projects:

http://inms-ienm.nrc-

cnrc.gc.ca/en/research/optical frequency projects e.php

Max Planck Institut für Quantenoptik http://www.mpq.mpg.de/mpq.html 